\title{
Johanson-Blizzard syndrome: A challenge in nasal reconstruction
}

\author{
Norma Timoney FDSRCS FRCS Plast, Michael J Weinberg MSc FRCSC, David A Ross FRACS, \\ Hugh G Thomson MS FRCSC FACS
}

\begin{abstract}
N Timoney, MJ Weinberg, DA Ross, HG Thomson. JohansonBlizzard syndrome: A challenge in nasal reconstruction. Can J Plast Surg 2004;12(2):81-85.

Johanson-Blizzard syndrome is rare and involves multiple congenital anomalies, including bilateral absence or deficiency of the nasal alae, giving the affected infant a characteristic appearance.

Two cases are described that illustrate the difficulties of nasal reconstruction in young children. Surgical options and the timing of intervention are discussed.
\end{abstract}

Key Words: Alar reconstruction; Johanson-Blizzard syndrome

\section{Le syndrome de Johanson-Blizzard : Un défi en reconstruction nasale}

Le syndrome de Johanson-Blizzard est rare. Il comporte des anomalies congénitales multiples, y compris une absence bilatérale ou une anomalie des ailes du nez, qui donne à l'enfant atteint une apparence caractéristique. Deux cas sont décrits qui illustrent les difficultés de la reconstruction nasale chez les jeunes enfants. Sont examinés les possibilités chirurgicales et le moment de prévoir l'intervention.

A nn Johanson and Robert Blizzard described this syndrome in 1971 (1). There are multiple associated congenital anomalies. The most apparent feature is bilateral absence of the nasal alae, which gives a distinctive appearance. Other anomalies include ectodermal scalp defects, microcephaly, wide and open fontanelles, sensorineural deafness due to abnormal development of the cochlea and petrous temporal bone, developmental delay, pancreatic insufficiency, hypothyroidism, and defects of the anorectal and genitourinary systems.

The nasal deformity consists of a small beak shaped nose with hypoplasia or even total absence of the alae. The upper lateral cartilages, the septum and its position on the nasal spine are relatively normal. The maxillae may be hypoplastic and there may be cleft-like defects of the medial orbit with associated abnormalities of the lacrimal ducts.

The aim of surgery is to correct the nasal tissue deficiency and improve the overall facial appearance.

Two cases are presented in which nasal reconstruction was performed.

\section{CASE PRESENTATIONS}

Case 1

A male patient was born at term with a low birth weight $(2.06 \mathrm{~kg})$, a length of $46 \mathrm{~cm}$ and a head circumference of $32 \mathrm{~cm}$. His parents are distant relatives of one another.

Dysmorphic facies were noted with hypoplastic nasal alae, deficiency of the supraorbital ridges, malars and absent upper lacrimal puncta (Figure 1). There was a midline scalp defect in the area of the vertex. Both anterior and posterior fontanelles were widely open, with the anterior fontanelle extending into

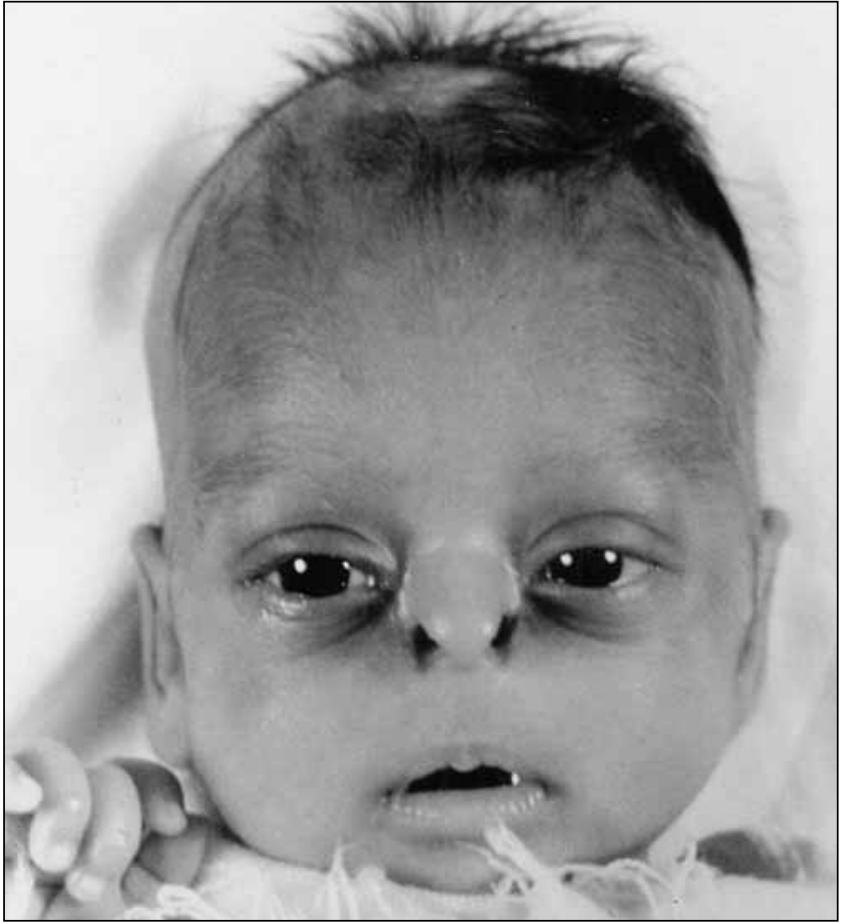

Figure 1) Infant demonstrating the characteristic hypoplastic nasal alae of Johanson-Blizzard syndrome

the glabellar region. Microcephaly was noted with a prominent occiput and an upsweep appearance of the frontal hair. There was congenital kyphosis with prolapse of the first lumbar vertebra. 


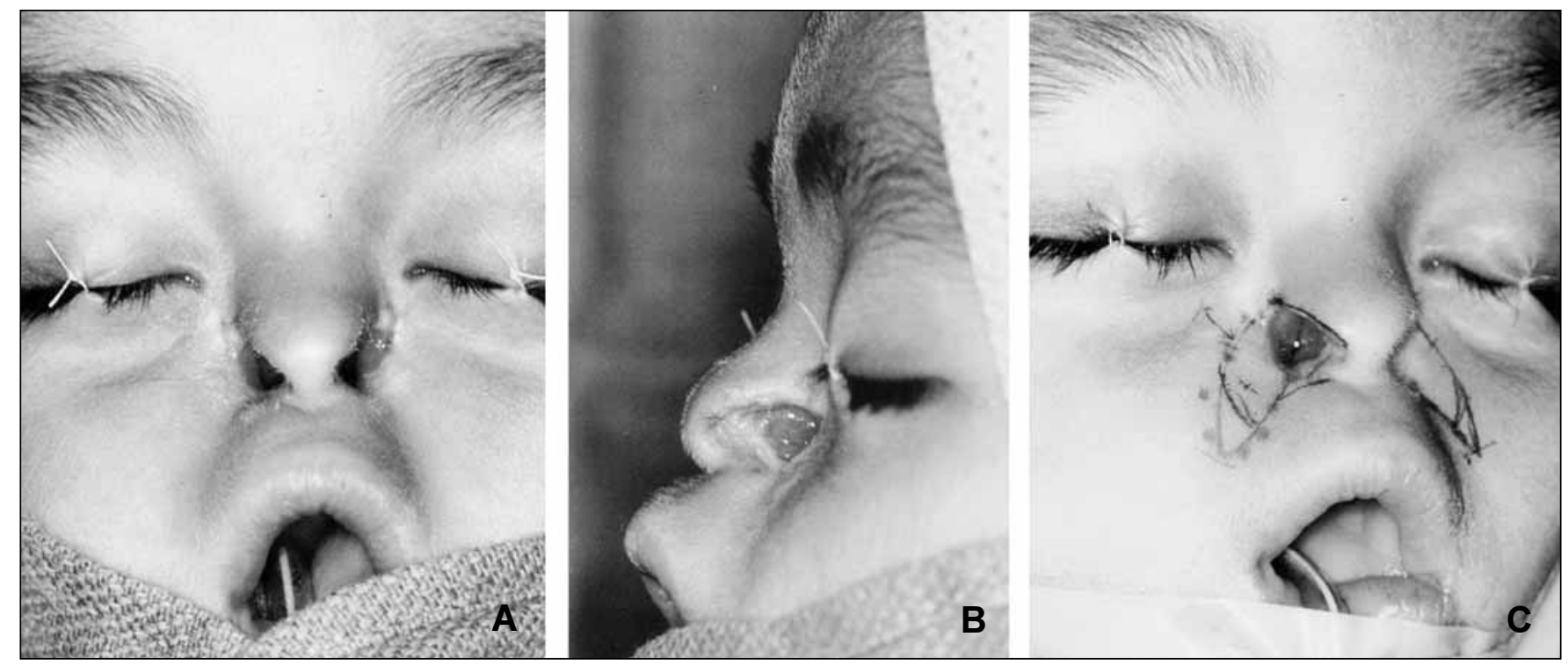

Figure 2) Operative planning. A Anteroposterior view of the defect; $\mathbf{B}$ Lateral view; C Nasolabial flaps outlined

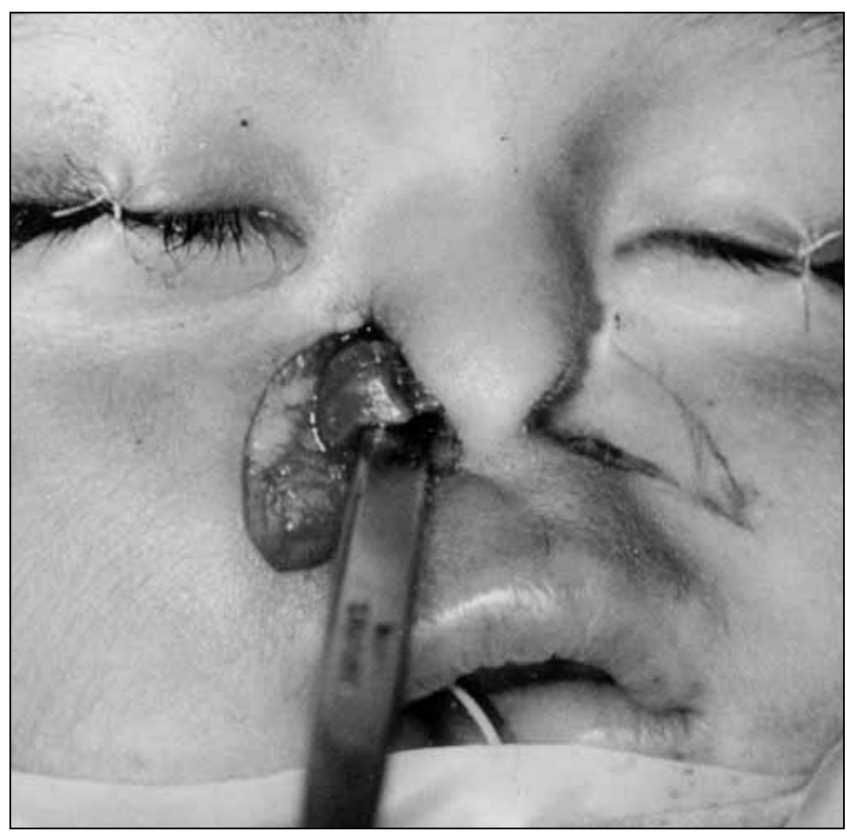

Figure 3) Bilateral nasolabial flaps were raised and folded over medially to provide lining to the absent alar area

Failure to thrive led to a diagnosis of pancreatic enzyme insufficiency and hypothyroidism. Sensorineural deafness was identified, and determined to be related to anomalous development of the cochlea.

His medical management involved gastrostomy feeding, Cotazym (Organon, Canada) to treat pancreatic insufficiency and thyroxine.

Surgical management included spinal fusion at the age of 11 months, followed by nasal reconstruction at the age of 18 months. Soft tissue reconstruction of the deficient alae was planned (Figure 2), and this involved the provision of lining tissue, and the consideration of support and covering skin.

Bilateral nasolabial flaps were raised and folded over medially to provide lining to the absent alar area (Figure 3 ). The resultant

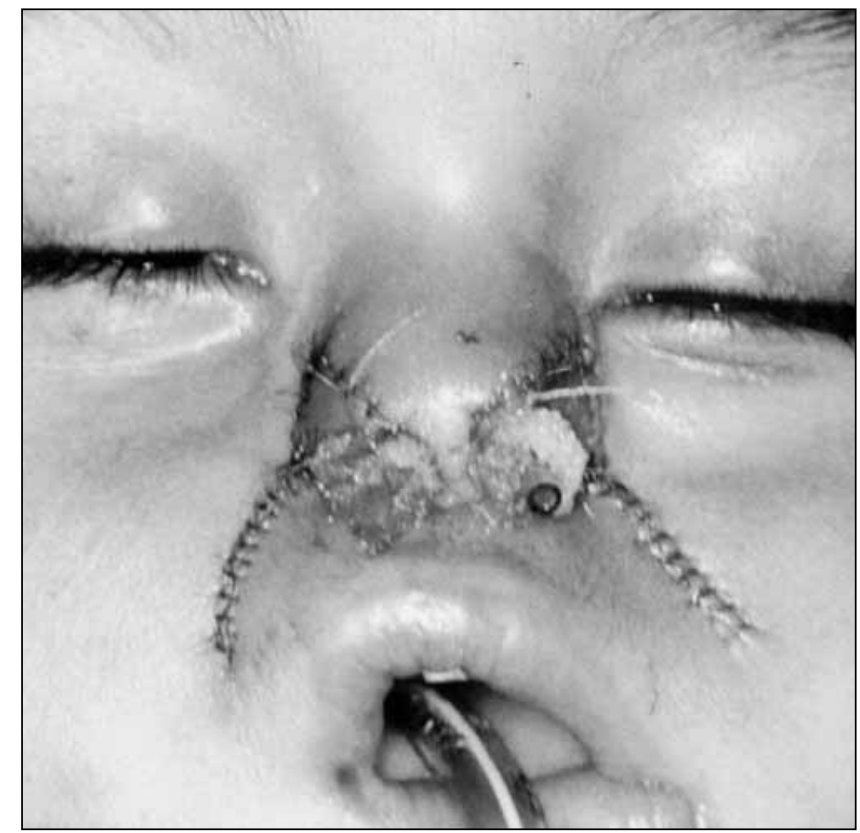

Figure 4) Reconstruction of the remaining surface defect at the site of the turned over flaps with bilateral full thickness postauricular skin grafts

donor defect was closed directly, leaving bilateral nasolabial scars. The remaining surface defect at the site of the turned over flaps was reconstructed with bilateral full thickness postauricular skin grafts (Figure 4). No structural support was provided, although an external nasal stent was used to prevent nostril collapse while awaiting scar maturation; this was followed with a Koken (2) nasal stent (a splint made of an elastic silicone polymer [dimethyl polysiloxane]) as long term therapy.

An ophthalmic surgeon investigated the lacrimal apparatus. The right lower lacrimal duct was found to be patent, but the left lower lacrimal duct ended in a blind sac.

Eight years later this child continues to have difficulties with feeding, deafness and developmental progress, and benefits from a Koken nasal stent (Figure 5). 


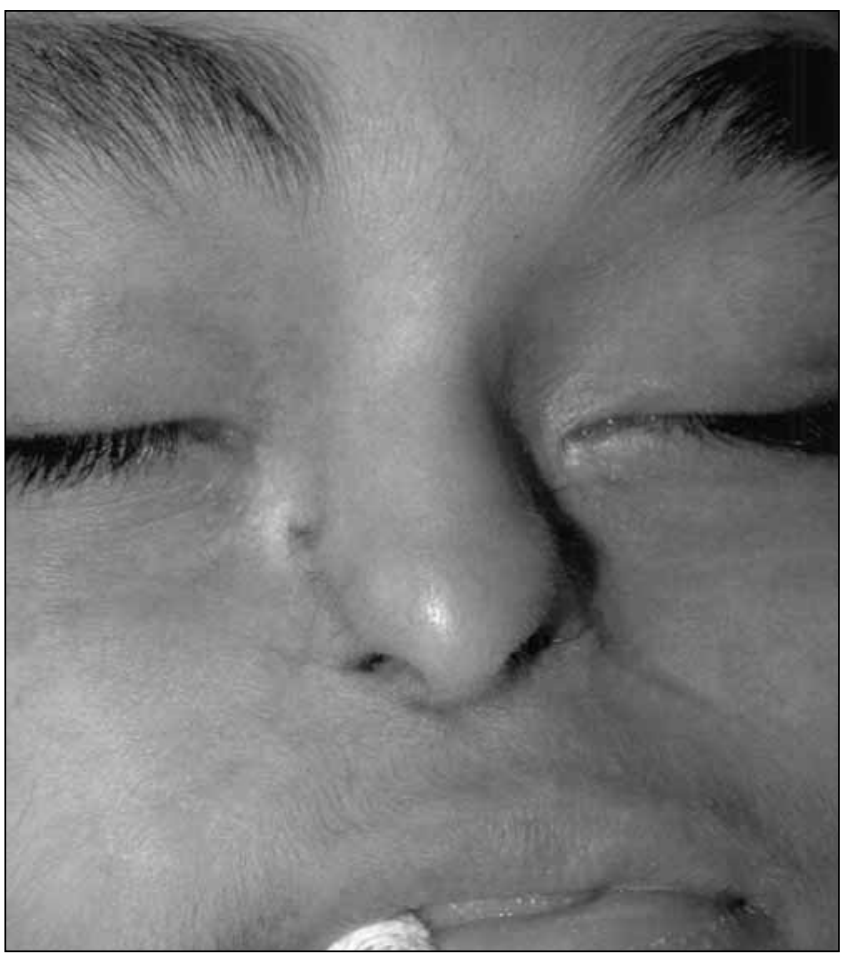

Figure 5) Long term follow-up view eight years after reconstruction

\section{Case 2}

A female child was born at term with a birth weight of $2.45 \mathrm{~kg}$, a length of $45 \mathrm{~cm}$ and a head circumference of $32 \mathrm{~cm}$. Her parents are first cousins. It was noted that she had characteristic absence of the nasal alae and cutis aplasia of the lambdoid area of the scalp. Bilateral lower lid colobomata were also noted (Figure 6). She had an imperforate anus and a rectovaginal fistula. Further investigation revealed an atrial septal defect with right bundle branch block, an obstructed upper pole of left kidney with a duplex ureter and bilateral abnormal cochleae.

She subsequently failed to thrive due to pancreatic insufficiency, required thyroxine supplements, and was developmentally delayed. During the first year of her life she had surgery related to her gastrointestinal and urinary problems on three occasions.

Having been assessed by the plastic surgery team after her birth, she underwent her first reconstructive procedure at the age of 18 months (Figure 7). The provision of nasal tissue, in terms of lining and skin cover, was planned to include cover for significant soft tissue deficiency of the lower eyelids due to the presence of medial colobomata.

Reconstruction was preceded by the initial insertion of two forehead tissue expanders. A rectangular tissue expander with a capacity of $170 \mathrm{~mL}$ was placed under the right forehead and a $200 \mathrm{~mL}$ round expander was placed on the left side (Figure 8).

Seven weeks after expansion, the reconstructive surgery was performed. Significant deformation of the frontal bone could be seen at this stage (Figure 9). Turned down nasal skin with the addition of short, turned over nasolabial flaps, was used as lining. No formal structural alar support was provided. The expanded forehead flap was used both to cover the dorsum of the nose and to add tissue in the area of the lower lid colobomata (Figure 10). Nasolacrimal probing was performed and bilateral medial canthopexies were also carried out.

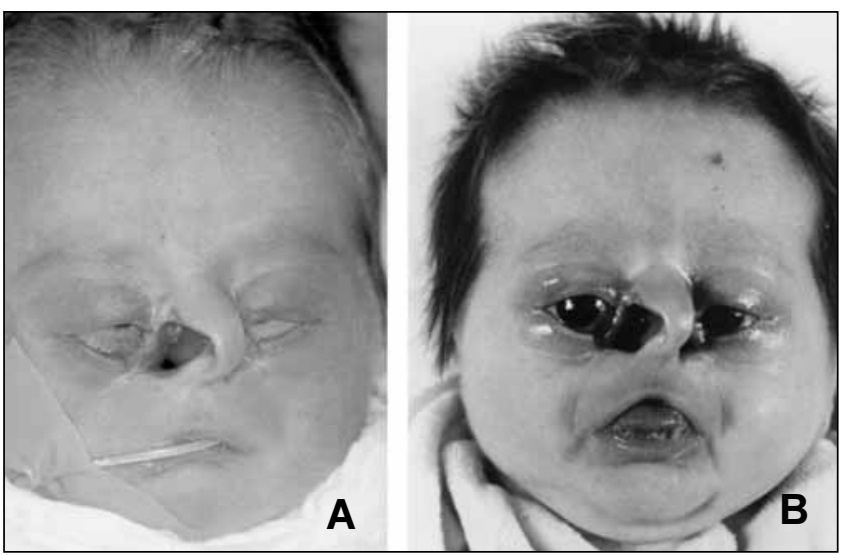

Figure 6) Early views of the child showing the magnitude of the defect. A Extensive right sided nasal alar defect and lower lid coloboma; B Bilateral defects shown with some asymmetry

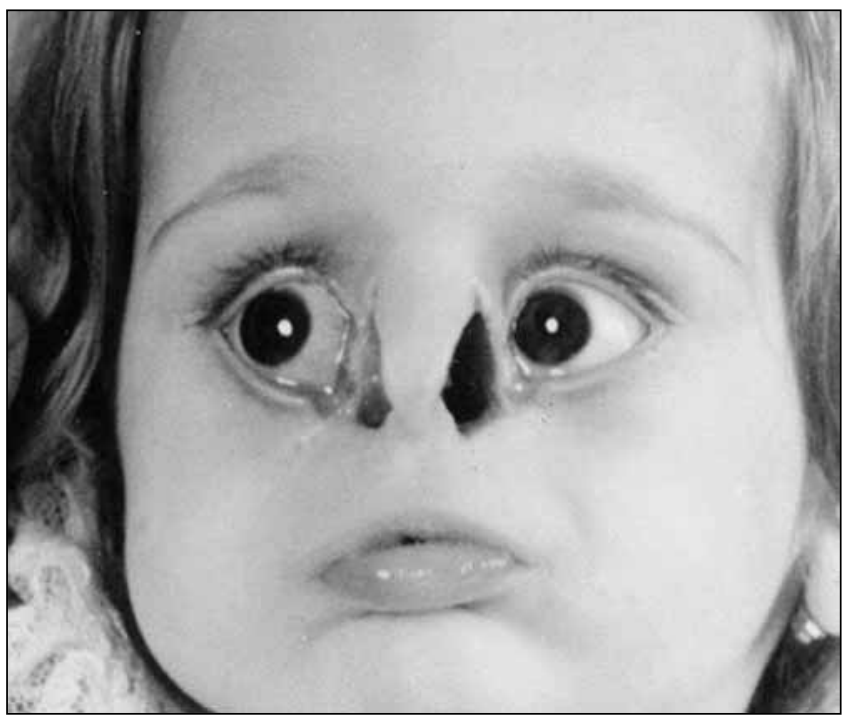

Figure 7) At age 18 months, the extent of the nasal defects is more clear and does not conform to classical subunit areas

Some adjustment to the level of the right eyebrow was subsequently necessary. Revision of the right side of the nasal reconstruction was also required and hair growth causing irritation of the right cornea was treated with laser depilation (Figure 11).

\section{DISCUSSION}

Johanson-Blizzard syndrome may be transmitted as an autosomal recessive condition, and the anomalies involved have been described in detail $(1,3-7)$. Plastic surgeons tend to be consulted early in the lives of these rare but characteristic looking patients. The absence or deficiency of the nasal alae presents difficulties with social interaction in a child with many other problems, including poor hearing, developmental delay and feeding difficulties. The defect poses a great challenge to the reconstructive surgeon in such young patients because relatively large defects of the nose are less commonly seen in children (8).

When planning reconstruction in these patients, careful consideration must be given to the timing of surgery as well as to the provision of lining, support and skin cover. Farkas et al (9), in 


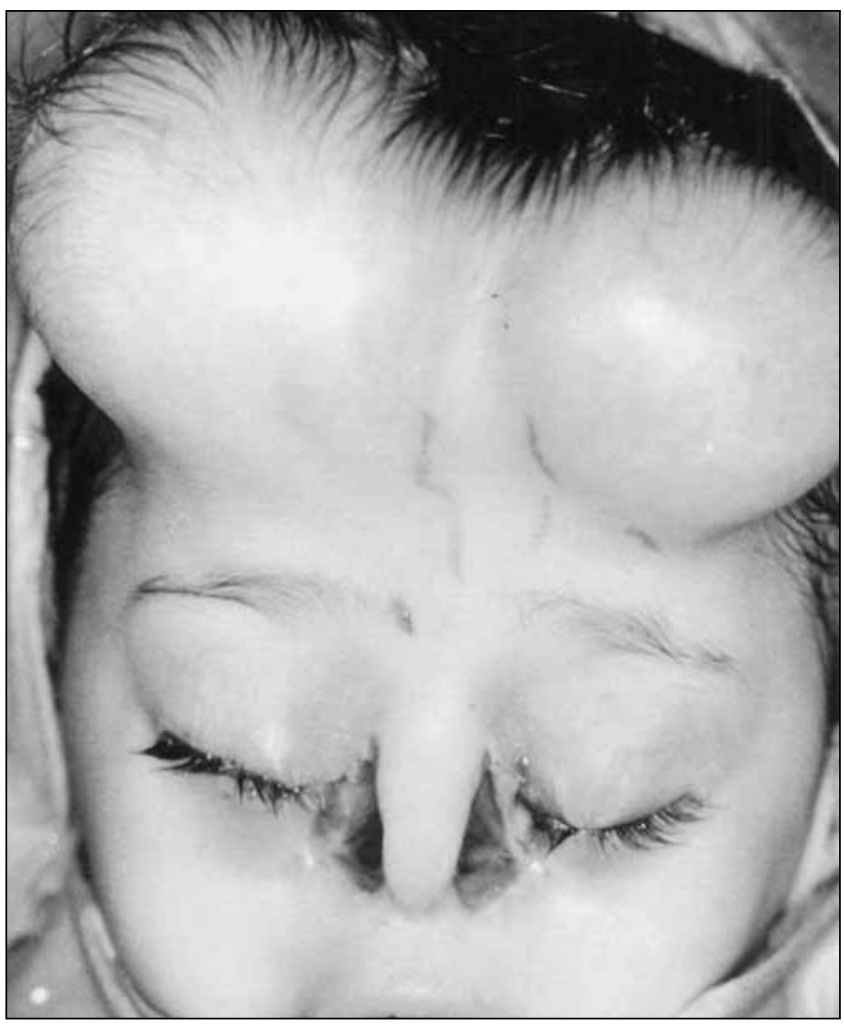

Figure 8) Insertion of two forehead tissue expanders. A rectangular tissue expander with a capacity of $170 \mathrm{~mL}$ was placed under the right forehead and a $200 \mathrm{~mL}$ round expander was placed on the left side

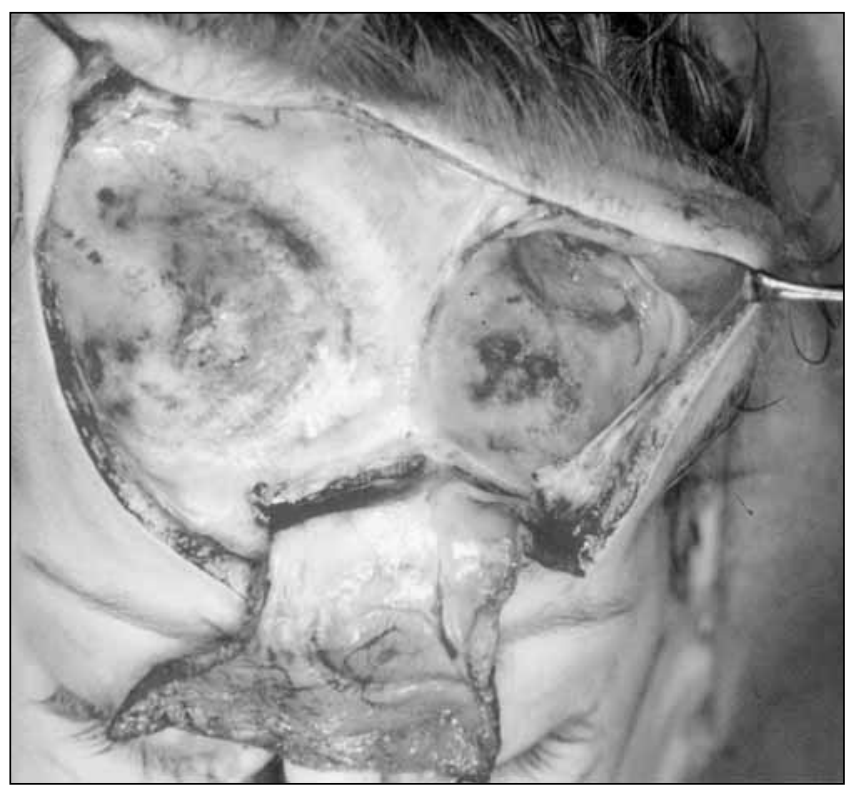

Figure 9) Significant deformation of the frontal bone seen following seven weeks of expansion

their extensive anthropometric measurements of the face, noted that nasal tip protrusion was the least developed of the nasal parameters by the age of one year and had achieved only $66 \%$ of its growth potential by the age of five years (9). The defects are bilateral and do not conform to traditionally

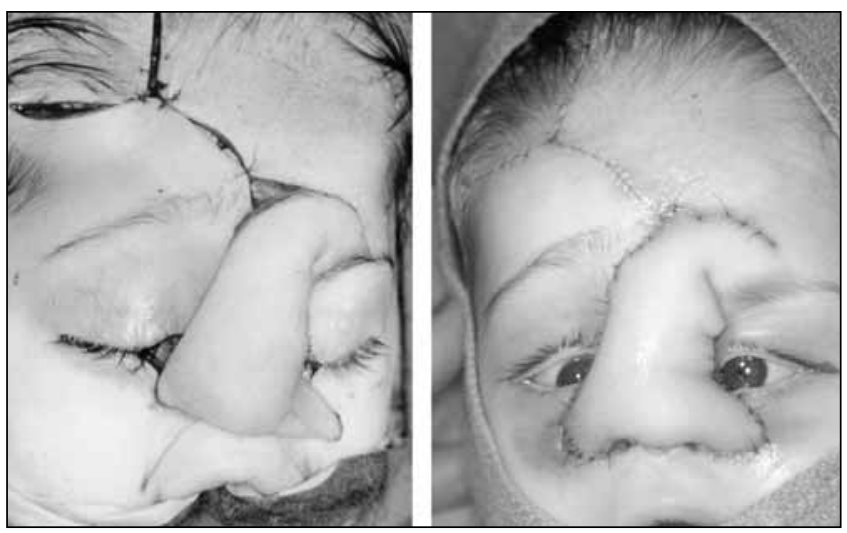

Figure 10) The expanded forehead flap was used both to cover the dorsum of the nose and to add tissue in the area of the lower lid colobomata

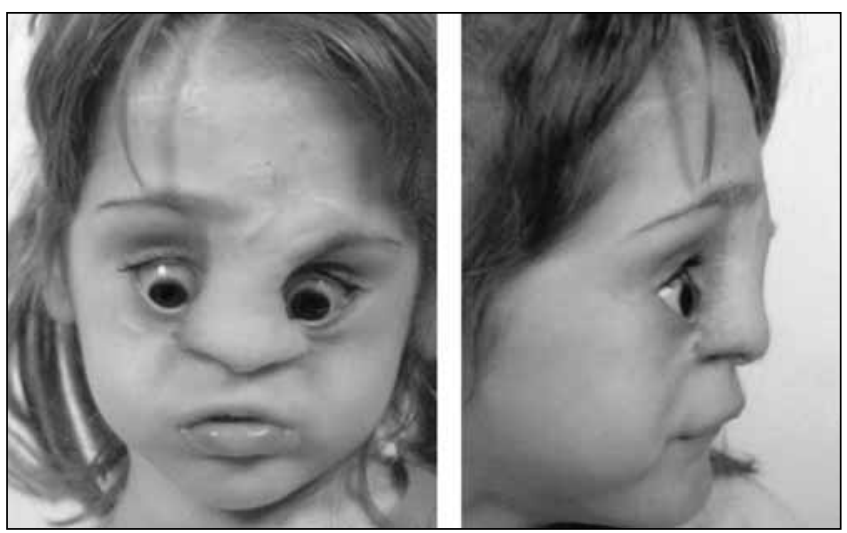

Figure 11) Some adjustment to the level of the right eyebrow was subsequently necessary. Revision of the right side of the nasal reconstruction was also required and hair growth causing irritation of the right cornea was treated with laser depilation

described subunits, so planning reconstruction in these cases is unhelpful.

Composite grafts may seem to be an ideal method, but the recipient defect in these cases is large and success in terms of graft survival is more uncertain. The donor site deformity would also be significant.

Unlike adult cases where trauma or malignancy has led to an alar defect, there is inadequate tissue to allow bipedicled alar lining flap, as described by Burget (10), to be used.

In case 1 , the less severe of the two cases, skin cover was provided with full thickness grafts harvested from the postauricular site and lining using local turned over nasolabial flaps. The use of grafts from this donor site could be criticized in view of the fact that these patients have hearing difficulties and potential donor site scarring could interfere with provision of hearing aids. However, this fortunately did not occur in case 1.

The use of the nasolabial flap may tend to narrow the airway but a Koken nasal stent was provided as a long term structural support for intrinsic scar maturation to occur (11). Formal cartilaginous reconstruction may be necessary when the patient is older.

In case 2, it was necessary to consider bilateral lower lid colobomata, as well as the nasal alar deficiency. Although lining could be provided using a combination of turned over nasolabial flaps and turned down nasal skin, skin cover was a 
greater challenge. A vertically oriented pre-expanded forehead flap was performed, although pedicled distant flaps using the G Tagliacozzi principle (12) may have been an option. The forehead flap has the advantage of good colour match with which to resurface the nose, but it has the disadvantage of tissue thickness with potential distortion of the eyebrow and the need for secondary adjustment surgery. Zuker et al (13) have described a pre-expanded forehead flap based on the superficial temporal artery that leaves a more aesthetically pleasing donor site scar at the level of the hairline.

Nasal reconstruction surgery in Johanson-Blizzard cases has been described previously by Fox et al (14). A series of three patients had been treated for absence of the nasal alae using a two-stage procedure. One side was treated at each stage using a turned over nasolabial flap as lining and a mitre type $\mathrm{v}-\mathrm{y}$ advancement of the dorsum of the nose for skin cover, making use of glabellar skin laxity. No cartilaginous support was thought necessary, though a specific follow-up period was not stated. The blood supply to the dorsal nasal flap at each stage seemed to be random.

Motashi et al (15) studied craniofacial growth characteristics in two Johanson-Blizzard cases and noted facial growth to be retarded, with greater effect on the maxilla than the mandible. Some authors have suggested that no treatment is required for the absent nasal alae before facial maturity (16). In view of the range of severity of the defect in these cases, the authors' belief is to the contrary, but surgery after the age of five years may have achieved better results when taking into account the growth and development of the nasal tip.

Koybashi et al (17) described a case with characteristic alar deficiency and bony cleft defects of the medial orbits. The patient described had a marked bony defect of the inferior orbital rims and less marked alar deficiency. At the age of 12 years, a complex reconstruction was carried out. This involved bony reconstruction with a U-shaped free vascularized iliac bone graft and bilateral island nasolabial flaps to reconstruct

\section{REFERENCES}

1. Johanson AJ, Blizzard RM. A syndrome of congenital aplasia of the alae nasi, deafness, hypothyroidism, dwarfism, absent permanent teeth, and malabsorbtion. J Pediatr 1971;79:982-7.

2. Yeow VK, Chen PK, Chen YR, Nordhoff SM. The use of nasal splints in the primary management of unilateral cleft nasal deformity. Plast Reconstr Surg 1999;103:1347-54.

3. Hurst JA, Baraister M. Johanson-Blizzard syndrome. J Med Genet 1989;26:45-8.

4. Morris MD, Fisher DA. Trypsinogen deficiency disease. Am J Dis Child 1967;114:203-8.

5. Schussheim A, Choi SJ, Silverberg M. Exocrine pancreatic insufficiency with congenital anomalies. J Pediatr 1976;89:782-4.

6. Jones NL, Hofley PM, Durie PR. Pathophysiology of the pancreatic defect in Johanson-Blizzard syndrome: A disorder of acinar development. J Pediatr 1994;125:406-8.

7. Trellis DR, Clouse RE. Johanson-Blizzard syndrome. Progression of pancreatic involvement into adulthood. Dig Dis Sci 1991;36:365-9.

8. Pittet B, Montandon D. Nasal reconstruction in children: A review of 29 patients. J Craniofac Surg 1998;9:522-8.

9. Farkas LG, Posnick JC, Hreczko TM, Pron GE. Growth patterns of the nasolabial region: A morphometric study. Cleft Palate Craniofac J 1992;29:318-24. the nasal floor. At a second stage a forehead flap was raised to provide skin cover with split calvarial bone graft for nasal structural support.

Neither of the patients described in this report has yet reached skeletal maturity and further procedures to address structural and bony support may be necessary. One patient has ongoing problems with stenosis of the nostril apertures.

Delaying intervention until skeletal maturity is difficult to justify when faced with a severe deformity, but further intervention is likely. Cartilaginous structural support in a young child's nose is difficult to provide and silicone splints provide only a partial solution.

\section{CONCLUSIONS}

Because the nasal deformity is one of the initial presenting features of Johanson-Blizzard Syndrome, a plastic surgery consultation is sought early in the child's life, although other medical and surgical interventions may take precedence. Two cases are described which reveal the difficulties in reconstruction of the nasal alae.

The extent of the defect may vary among patients, and underlying bony defects of the maxilla may be present. Traditional options, such as a forehead flap or nasolabial flap, are useful. Local nasolabial flaps are useful for lining provision.

For a larger defect, a pre-expanded forehead flap based on the superficial temporal artery may provide adequate tissue for lining and cover with an acceptable donor site. Nasal stents may provide an interim alternative to the provision of cartilaginous batten grafts.

Delaying reconstruction until after the age of five years may prevent the need for later adjustments when surgery is performed early, though nasal tip protrusion has reached only $66 \%$ of its potential by then and is not at its mature position until the ages of 14 years to 16 years. Any bony clefting needs consideration when nearing skeletal maturity.

10. Burget G. Aesthetic restoration of the nose. Clin Plast Surg 1985;12:463-80.

11. Nakajima T, Yoshimura Y, Sakakibarra A. Augmentation of the nostril splint for retaining the corrected contour of the cleft lip nose. Plast Reconstr Surg 1990;85:182-6.

12. Cormack GC, Lamberty GH. The Arterial Anatomy of Skin Flaps. Edinburgh: Churchill Livingstone, 1994:48-9.

13. Zuker RM, Capek L, de Haas W. The expanded forehead scalping flap: A new method of total nasal reconstruction. Plast Reconstr Surg 1996;98:155-9.

14. Fox JW, Golden GT, Edgerton MT. Surgical correction of the absent nasal alae of the Johanson-Blizzard syndrome. Plast Reconstr Surg 1976;57:484-6.

15. Motohashi N, Pruzansky S, Day D. Roentgencephalometric analysis of craniofacial growth in the Johanson-Blizzard syndrome. J Craniofac Genet Dev Biol 1981;1:57-72.

16. Day DW, Israel JN. Johanson-Blizzard syndrome. Birth Defects Orig Artic Ser 1978;14:275-87.

17. Kobayashi S, Ohmori K, Sekiguchi J. Johanson-Blizzard syndrome facial anomaly and its correction using a microsurgical bone graft and tripartite osteotomy. J Craniofac Surg 1995;6:382-5. 